$\begin{array}{lllll}\text { Motrivivência } & \text { v. } 26, & \text { n. } 42, & \text { p. } 238-249, & \text { junho/2014 }\end{array}$

http://dx.doi.org/10.5007/2175-8042.2014v26n42p238

\title{
A PRÁTICA DA CULTURA ESPORTIVA NAS AULAS DE EDUCAÇÃO FÍSICA
}

Roberta Bevilaqua de Quadros'

Daniela Stefanello²

Rosalvo Luis Sawitzki ${ }^{3}$

\section{RESUMO}

Este trabalho pretende demonstrar a prática da iniciação esportiva nas aulas de Educação Física, como atividades complementares, enfatizando o desenvolvimento dos alunos. $\mathrm{O}$ estudo constitui-se de um relato de experiência em que foi desenvolvido com o $6^{\circ}$ ano em uma Escola Estadual através do Subprojeto "Cultura Esportiva da Escola" da Universidade Federal de Santa Maria. O desenvolvimento do projeto proporcionou aulas diversificadas para que todos os alunos, no contexto das suas diferenças, pudessem participar, dessa maneira é possível estimulá-los nos domínios motor, cognitivo e afetivosocial. Apesar das dificuldades encontradas durante a prática docente, houve resultados positivos no andamento das atividades.

Palavras-chave: Educação Física Escolar; Intervenção Profissional; Pedagogia do Esporte.

1 Aluna do curso de Especialização em Pesquisa em Movimento Humano, UFSM, Santa Maria/Rio Grande do Sul, Brasil.

E-mail: robertabevilaqua@yahoo.com.br

2 Especialista em Educação Física Escolar. UFSM, Santa Maria/Rio Grande do Sul, Brasil.

E-mail: danstefanello@hotmail.com

3 Doutor em Educação. Professor do Centro de Educação Física e Desportos da Universidade Federal de Santa Maria, UFSM, Santa Maria/Rio Grande do Sul, Brasil.

E-mail: rosalvols@hotmail.com 


\section{INTRODUÇÃO}

O estudo apresenta a prática da cultura esportiva nas aulas de Educação Física em uma escola da rede pública. Essa prática está inserida no Subprojeto "Cultura Esportiva da Escola" do Programa Institucional de Bolsa de Iniciação à Docência - PIBID, do Centro de Educação Física e Desportos - CEFD da Universidade Federal de Santa Maria - UFSM.

Conforme o portal da Coordenação de Aperfeiçoamento de Pessoal de Nível Superior - CAPES, o Programa Institucional de Bolsa de Iniciação à Docência - PIBID é uma iniciativa de aperfeiçoamento e valorização da formação inicial de professores para a educação básica. O programa consiste em conceder bolsas de iniciação à docência a alunos de licenciatura participantes de projetos de iniciação à docência desenvolvida por Instituições de Educação Superior (IES) em parceria com escolas de educação básica da rede pública de ensino. Os projetos desenvolvidos pelas IES devem promover a inserção dos graduandos no contexto das escolas públicas desde a formação inicial acadêmica para que desenvolvam atividades didático-pedagógicas com orientação de um docente da licenciatura e de um professor da escola.

Nesse caso, o Subprojeto "Cultura Esportiva da Escola" / PIBID realiza atividades complementares que são ministradas por acadêmicos em formação inicial, os quais são bolsistas do Ministério da Educação (ME) e CAPES. O Subprojeto "Cultura Esportiva da Escola" possui em sua essência, articular o conhecimento que a Universidade proporciona na formação inicial, visando à prática da docência na escola. Esse conhecimento a ser praticado na escola, tange a disciplina de Educação Física e refere-se à prática esportiva desenvolvida de forma complementar as aulas curriculares. $\mathrm{O}$ objetivo desse Subprojeto é trabalhar com as dificuldades que os alunos possuem tanto no aspecto motor quanto cognitivo e social. Essas atividades complementares surgem a partir das demandas da escola, principalmente no que se refere à necessidade da aprendizagem do aluno em sua formação.

O desenvolvimento do Subprojeto "Cultura Esportiva na Escola" teve como foco de ação criar um campo de atuação na docência de educação básica aos futuros educadores em formação inicial e estimular a formação continuada. Com isso, foi possível desenvolver práticas educacionais e construir estratégias para facilitar o ensino-aprendizagem na área de Educação Física Escolar. Essas estratégias utilizadas nas aulas de Educação Física surgiram para auxiliar na compreensão dos conteúdos pelos alunos, sendo uma forma de aproximar com mais clareza o entendimento e a realização dos movimentos, jogos e atividades.

Dessa forma, a prática da cultura esportiva nas aulas de Educação Física surgiu pela necessidade de desenvolver com os alunos a prática da iniciação esportiva, incentivando-os ao entendimento não somente do praticar pelo praticar, e sim pela aprendizagem cognitiva, motora e pela socialização. Esse praticar pelo praticar mencionado aqui, não prevalece somente o jogar pelo jogar, e sim a participação do professor, instigando-os a pensar e a refletir sobre o movimento os quais realizam durante esse processo, e também sobre a relação com seus colegas durante o jogo. Além da capacidade motora, o aluno necessita perceber seus movimentos e raciocinar o que pode evoluir ou mudar, e ainda identificar 
a importância do convívio com a turma. Questões importantes como o consumismo, o marketing podem ser abordados em sala de aula para que o aluno entenda que, além do esporte e do jogo existem outros fatores determinantes.

Segundo as Lições do Rio Grande (2010), os conhecimentos transmitidos pela prática esportiva na escola, não devem ser os mesmos oportunizados pelas instituições não escolares que, sistematizam as práticas corporais, focalizando no rendimento e na perfeição dos movimentos, como por exemplo, "escolinhas" de futsal, escolas de ballet, entre outros. A Educação Física como disciplina deve ter claro que não possui as mesmas finalidades dessas "escolinhas", mas é importante que não desconsidere na escola. $\mathrm{O}$ fato de não desconsiderar as finalidades das escolinhas dentro da escola, é para que os alunos compreendam as diversas formas de vivenciar o esporte, como esporte de lazer, participativo e de rendimento. É essencial desenvolver no aluno o entendimento crítico e consciente dessas diversas formas de vivenciar o esporte.

O Subprojeto tem em sua essência além da prática, privilegiar a participação do coletivo em suas ações através da realização semanal de grupo de estudos com o objetivo de dialogar sobre as diferentes leituras realizadas. A interligação com outros subprojetos de forma interdisciplinar foi fundamental para o resgate do sentido e significado com vários espaços da cultura esportiva escolar e seu entorno. Os acadêmicos, bolsistas do projeto, estão subsidiados por toda uma rede de apoio, constituída pelos professores do curso de graduação de Educação Física do CEFD/UFSM, por professores supervisores da escola, orientador do subprojeto, alunos da escola, comunidade escolar e o suporte de equipamentos e materiais previstos (QUADROS e SAWITZKI, 2011).

Para o desenvolvimento da prática pedagógica, alguns autores permearam os grupos de estudos nas discussões, os quais foram: Valter Bracht (1996), Mauro Betti (2002), Luiz Roberto Zuliani (2002), Fernando Jaime González (2006), Elenor Kunz (2006), Rosalvo Luis Sawitzki (2006), Paulo Evaldo Fensterseifer (2006), Amauri Aparecido Bassóli de Oliveira (2004).

O referente estudo priorizou demonstrar a prática da iniciação esportiva nas aulas de Educação Física, como atividades complementares, enfatizando o desenvolvimento dos alunos nessas aulas.

\section{Educação Física escolar e o esporte}

Sabe-se que a disciplina de Educação Física abrange vários conteúdos, como a dança, ginástica, lutas, jogos motores, atividades lúdicas e recreativas, atividades expressivas, atletismo, esportes coletivos e individuais, os quais são importantes e possuem seus respectivos valores. Assim, o esporte é um dos vários conteúdos que a Educação Física pode propor em suas aulas a fim de que os alunos possam vivenciar a cultura corporal do movimento.

Betti e Zuliani (2002) descrevem que o dever da Educação Física, como componente curricular da Educação Básica, é assumir a função de:

(...) introduzir e integrar o aluno na cultura corporal de movimento, formando o cidadão que vai produzi-la, reproduzi-la e transformá-la, instrumentalizando-o para usufruir do jogo, do esporte, das atividades rítmicas e dança, das ginásticas e práticas de aptidão física, em benefício da qualidade de vida. "A integração que possibilitará o usufruto da 
cultura corporal de movimento há de ser plena - é afetiva, social, cognitiva e motora. Vale dizer, é a integração de sua personalidade" (p. 75).

\section{A Educação Física Escolar e o} esporte possuem uma ligação forte. Mas, geralmente o esporte praticado na escola enfatiza a competição, o individual, alunos que se destacam nas habilidades motoras e cognitivas, deixando de lado, aqueles que não possuem muitas habilidades para os esportes. Nesse sentido, a disciplina de Educação Física precisa privilegiar o coletivo, a participação de todos e todas aos esportes, não objetivando ao rendimento, e sim ao lazer e também ao aprendizado de cada movimento e a convivência com os colegas.

Segundo as Lições do Rio Grande (2010), a disciplina de Educação Física proporciona aos alunos que conheçam e contemplem as diversas práticas corporais sistematizadas, abrangendo suas particularidades e os significados concedidos. Com isso, a aula desta disciplina necessita contemplar a gama de conteúdos a que oferece e não apenas submeter os alunos em poucas vivências.

Kunz (2006) cita que o ensino da Educação Física não visa apenas o desenvolvimento das ações do esporte, e sim, propiciar aos alunos o entendimento crítico das várias formas da representação esportiva, juntamente com seus problemas ligados ao contexto sociopolítico. Por meio dessa reflexão é permitido compreender que, o aluno precisa além das ações de cada esporte, também o entendimento dessas ações no contexto escolar e no contexto social, como abarcar os temas que envolvem a prática e o gosto pelo esporte.

Conforme Kunz (2006), o esporte é definido como prática social de origem histórico-cultural a qual necessita ser interrogado como conteúdo pedagógico em relação às normas, à realidade social e cultural de quem o pratica, cria e recria. O aluno deve compreender que a prática esportiva não é somente o jogar, apenas objetivando o vencer, mas sim que existem valores sociais e morais, normas e regras a obedecer, o que garantem o direito à prática do esporte. O mesmo autor faz referência a uma das questões metodológicas para o ensino dos esportes em que o aluno deve obter conhecimento suficiente para criticar e compreender o esporte em relação a seus valores e normas sociais e culturais.

Segundo o Coletivo de autores (1992), é importante que as habilidades, as atividades corporais e o domínio da técnica se relacionem entre si para um bom desempenho do jogo. Mas não enfatizando a ideia de equipe com o objetivo de vencer, e sim no coletivo para a compreensão das determinações de um jogo. Assim, as mudanças qualitativas dependem da coletividade, dos valores éticos, morais e políticos, tanto o erro como o acerto, juntamente com as habilidades e domínio técnico, o que não significa que as mudanças qualitativas não se pautem nas táticas, nas técnicas, nas relações sociais e instituições sociais, entre outros.

O esporte pode ser trabalhado para que o aluno desenvolva autonomia, interação social, objetividade, entre outros, o que auxilie na sua formação. Conforme Brodtmann/Trebels (1979), citado por Kunz (2006), o esporte escolar para a sua compreensão, deve ir além da prática e deve ser compreendido nas dimensões das capacidades de saber e entender a situação em que os outros participantes encontram-se no esporte e, juntamente com os que não possuem habilidades avantajadas que a 
modalidade impõe. Ainda, ter a capacidade de visualizar elementos que influenciam no campo esportivo, como mercantilização e possuir capacidade de visão crítica para avaliá-lo. Segundo o mesmo autor, que o aluno possa instrumentalizar esses conhecimentos da prática de esportes e oportunizar na comunicação dentro e fora da escola.

Kunz (2006) relata que, com esses questionamentos e críticas, o esporte passa por uma transformação didática - pedagógica para atender o ensino de todos os participantes e não apenas de uma minoria. Desta forma, a intenção da escola é fazer do esporte um objeto de aprendizagem sistemática e formal, uma linguagem complementar e de ação. A escola é fundamental nesse processo de transformação didática do esporte, é nela que esse processo irá desenvolver e estimular seus alunos a ter o acesso ao esporte. E é nesse sentido que a comunicação entre alunos e professor é fundamental para que as ações e o entendimento sejam construídos de forma clara e objetiva no processo de ensino- aprendizagem. Essas interações servem para fortalecer as relações afetivas dos alunos, contribuindo para suas vidas além do ambiente escolar. Conforme Kunz (2006), a relação que a Educação Física estabelece com seus alunos é de contribuir no desenvolvimento da personalidade e das habilidades motoras em geral, e que o aluno possa organizar seu tempo livre, e adequar-se às exigências sociais.

O papel do professor de Educação Física no processo de ensino-aprendizagem é essencial para que seus alunos sintam-se seguros para o desenvolvimento das atividades e na motivação de aprender com o que está sendo realizado. O fato não é somente dar aulas e sim envolver os alunos ao conteúdo planejado, enfatizando a compreensão, e também a interação dos estudantes na construção dos objetivos em cada conteúdo.

\section{METODOLOGIA}

O trabalho está constituído de um relato de experiência vivido dentro de uma instituição pública, baseado no ensino da cultura esportiva, desenvolvida com alunos da $5^{\mathrm{a}}$ série ou $6^{\circ}$ ano por meio do Subprojeto "Cultura Esportiva da Escola". E foi realizado em uma Escola Estadual de Ensino Fundamental localizada na região urbana da cidade de Santa Maria, RS.

A turma escolhida para o relato de experiência foi a do $6^{a}$ ano do ensino fundamental - séries finais, pois é neste momento em que os alunos têm sua iniciação esportiva. O fato de estar no início dessa prática, o relato de experiência, certamente foi mais detalhado, o que possibilita explicar as atividades realizadas, as experiências vividas pelos alunos e os resultados obtidos dessa vivência.

A experiência foi realizada no período de um (1) ano, a partir de maio de 2010, o qual se iniciou as atividades complementares na escola, até maio de 2011, onde finalizou a participação de alguns acadêmicos, pelo motivo de conclusão do curso, mas as atividades ainda permaneceram com outros acadêmicos bolsistas. As aulas foram realizadas nesse período, onde havia quatro aulas semanais (duas para meninas e dois para meninos) no período de 50 minutos, totalizando dezesseis (16) aulas por mês. Essas atividades foram realizadas no turno inverso das aulas, em que a turma era separada por sexo.

A escolha da escola em questão seguiu alguns requisitos orientados pelo 
professor coordenador do Subprojeto, como ser escola estadual (previsto nas normas do Ministério da Educação), possuir disponibilidade de implantação do projeto. Como a equipe diretiva da escola recebeu de forma receptiva a proposta de implantação do subprojeto, iniciaram-se as atividades em maio de 2010. A estrutura física da escola era composta de ginásio, sala de dança, pátio com areia e pracinha, mas a prática da iniciação esportiva era realizada somente no ginásio. A faixa etária dos alunos era de 10 e 11 anos, pertencentes a famílias de baixo e médio poder aquisitivo.

O subprojeto aconteceu em quatro diferentes momentos e com o objetivo de auxiliar e facilitar a prática docente dos acadêmicos, perante os alunos no ambiente escolar. A seguir será apresentado os quatros momentos e seus respectivos acontecimentos.

O primeiro momento, antes da execução da prática, ocorreu com a necessidade de realizar a sondagem e o diagnóstico situacional a fim de verificar o comportamento em que os alunos da quinta série ou do sexto ano encontravam-se nas ações que estavam vivenciando. Essas ações equivalem às atividades e conteúdos que os alunos estavam aprendendo e experienciando, o que equivale aos conhecimentos procedimentais, conceituais e atitudinais. Esse diagnóstico visou saber quais atividades em que os alunos estavam envolvidos, sendo possível, aprofundar as atividades e melhorar o entendimento dos alunos nas atividades, juntamente com a evolução da capacidade motora. Com isso, foram observados os conhecimentos procedimentais, significando como executavam as ações e o que sabiam fazer, os conhecimentos conceituais, saber sobre o que estavam executando, e os conhecimentos atitudinais, que abrangia a convivência com os colegas e professores. O diagnóstico sobre o ambiente físico foi descrever os espaços disponíveis para a prática que a escola oferecia.

Após esse diagnóstico, ocorreu o segundo momento e que abrangeu o grupo de estudos, onde as observações foram estudadas e discutidas pelos acadêmicos, professor supervisor e professores da escola envolvidos no programa para determinarem a melhor forma de planejamento dessas aulas. As observações focaram a prática esportiva da escola, o andamento do semestre e seu funcionamento, juntamente com o debate do projeto político pedagógico e do plano de estudo da Educação Física das turmas em questão. Desse modo, houve planejamento dos conteúdos a ser desenvolvidos como atividades complementares em relação aos esportes e jogos, nos quais foram: vôlei, futsal, handebol e basquetebol, desenvolvidos tanto para meninos quanto para meninas.

$\mathrm{O}$ terceiro momento foi direcionado para os acadêmicos atuarem diretamente nas aulas complementares de Educação Física, juntamente com a participação nos eventos realizados pela escola e elaboração de atividades em datas especiais. O plano de aula foi constituído de objetivos geral e específico, as atividades que eram realizadas e a avaliação. Essa avaliação acontecia a cada final de aula, em que os acadêmicos responsáveis realizavam a reflexão sobre o decorrer das atividades. Além disso, a avaliação ocorria juntamente com os alunos através do feedback no final da aula, onde os alunos expunham o que haviam compreendidos.

O quarto momento deu-se pela avaliação do que estava sendo realizado. Este momento acontecia semanalmente no grupo de estudos, e se debatia sobre as 
dificuldades que estavam surgindo durante as aulas, e ainda havia leituras de artigos e textos, sendo um material de apoio para auxiliar no decorrer das atividades.

\section{A experiência}

As observações realizadas contribuíram para que fossem identificadas as dificuldades apresentadas pelos alunos nos seguintes itens: ação que os alunos estavam vivenciando nos conhecimentos procedimentais (saber fazer, praticar), nos conhecimentos conceituais sobre a ação (saber falar, conhecer), e nos conhecimentos atitudinais (saber ser), as atitudes de jogadores com (colegas e adversários) relações afetivas antes/durante e após a realização do jogo, as atitudes dos jogadores com os/as colegas (passar; dividir tempos; ajudas; respeito às regras e ao concordado) e as observações de situações peculiares. Essas observações ajudaram os acadêmicos a perceber o nível de desenvolvimento motor, cognitivo e afetivo-social que se encontravam os alunos em questão.

A coleta de informações do processo ensino-aprendizagem ocorreu para refletir e verificar se os objetivos estavam sendo atingidos, e assim, podendo modificar, progredir, ressignificar a ação docente, respeitando as diferentes etapas do desenvolvimento motor do aluno, bem como a sua diversidade. As diferentes etapas do desenvolvimento motor de cada aluno foram observadas no decorrer das atividades, no intuito de perceber em que ações e que momentos eles tinham mais dificuldades motoras. Alguns alunos sobressaíam mais que os outros, pelo fato do estímulo e também por gostar muito do que estavam realizando. Percebeu-se que todos os estudantes são diferentes e que, cada um possui suas capacidades e habilidades, sendo necessário que o professor respeite o desenvolvimento de cada aluno, mas também os auxilie para a evolução.

Segundo Kunz (2006), o professor, tendo em vista dos esportes que pretende ensinar, deve analisar o conhecimento, as influências sobre todas as modalidades que possuem os alunos, juntamente com os locais e os materiais que a escola disponibiliza. O mesmo autor cita que na forma prática do esporte, deve haver um trabalho conjunto entre professor e aluno, salientando a importância de desenvolver a intenção de agir pelo esporte, e também que os alunos possam aprender e compreender a melhor maneira que o esporte oferece e poderá ter para o seu contexto. Nessa perspectiva, é bom lembrar que o aluno não está isento de informações e conhecimentos sobre os esportes, sendo assim, é necessário que o professor considere essas questões para que auxilie no processo de ensino. Além, de conhecer os espaço físico e os materiais que estão disponibilizados para o andamento das aulas. O diálogo entre professor e alunos é fundamental para que a prática do esporte seja debatida e compreendida nas suas diversas formas, assim, como sua execução no contexto em que os alunos estão inseridos.

Durante as aulas, buscou-se transmitir aos alunos a compreensão de como o convívio das práticas esportivas são importantes para o andamento das aulas, o que possibilita um ambiente propício para a realização das atividades e para a integração dos colegas. É fundamental que os alunos possam compreender a Educação Física como disciplina que possui conteúdos a ser ensinados e transmitidos, em um ambiente propício à descontração e a aprendizagem. 
O desenvolvimento das aulas proporcionou a criação e/ou modificação de regras; o cumprimento de regras; e o prazer de estar em grupo, fugindo do foco de ganhar ou perder. Por exemplo, nos jogos coletivos realizados durante as aulas, a condição para ser validado um ponto, era que todos os integrantes de uma equipe tocassem na bola, incentivando assim, o trabalho em equipe. Particularmente, no jogo de vôlei das meninas, pelas dificuldades que apresentavam inicialmente, era permitido segurar a bola para depois passá-la adiante, ou ainda, a utilização de duas bolas em jogo para estimular a atenção das alunas, o que caracterizou como estratégias no trabalho de iniciação ao esporte para a aprendizagem dos fundamentos básicos. Outra atividade interessante vivenciada pelos alunos, e que pode ser utilizada para ensinar qualquer esporte, é o desafio de acertar o alvo ou o trabalho de ataque e defesa.

Essas e outras estratégias foram fundamentais para o progresso do aluno na aprendizagem dos esportes, melhorando o processo ensino-aprendizagem. Segundo Oliveira e Paes (2004), nos conteúdos de ensino, devem ser trabalhados o desenvolvimento da destreza e habilidades motoras, sem a preocupação com as vitórias, sendo que na infância e na adolescência a capacidade de suportar as experiências nos jogos é mais fácil por terem a compreensão simplificada das regras e os resultados das ações e não por títulos a serem alcançados.

Durante as aulas foram desenvolvidas atividades que servem de base para a aprendizagem dos esportes como, por exemplo, jogo "caçador", o jogo "bandeirinha", o jogo "bobinho", "fogueirão", estafetas de acertar o alvo, utilizando diferentes tipos de bolas, etc. Com essas e outras atividades, os alunos tiveram a oportunidade de trabalhar o esquema corporal, espaço, raciocínio lógico, lateralidade, ritmo, equilíbrio, controle muscular, percepção auditiva, tempo, coordenação motora, força, velocidade, etc. Cada aula foi planejada e desenvolvida dentro de um objetivo específico, relacionadas a um determinado esporte. $\mathrm{E}$, também foram aplicadas de maneira que todos pudessem vivenciar tanto os fundamentos dos esportes, quanto a prática do jogo propriamente dito, pois cada aula foi dividida em atividades, exercícios diversos e o jogo no final, para incentivar o trabalho em equipe. A cada aula que passava, os alunos dominavam mais os fundamentos dos esportes, e demonstravam participação e colaboração.

A dificuldade está na diferença de interesse entre os alunos, no que se refere à descontração e o aprendizado. Torna-se necessário a compreensão dos alunos sobre a diferenciação entre compreender a aula como um momento para todos vivenciarem e desfrutarem, e não como sendo um momento onde o aluno que possui maior facilidade está livre para fazer o que quiser. Segundo as Lições do Rio Grande (2010), a Educação Física como componente curricular responsável por tematizar à cultura corporal de movimento, tem por objetivo fazer com que o aluno seja um sujeito ativo, crítico e criativo na dimensão social. Para que isso aconteça, é necessário explicitar as competências e conteúdos referentes a esta disciplina, e fazer com que o aluno progrida nas suas características sociocognitivas nas diferentes etapas escolares e no processo de conhecimento.

Durante o processo das atividades, alguns alunos passaram pela situação contrária, sentindo maior dificuldade em 
assimilar alguns conteúdos. Nestes casos, houve momentos de atenção especial a estes alunos, em que o professor buscou pessoalmente auxiliar no aprendizado de cada uma de suas dificuldades apresentadas.

A atuação do Programa na Escola foi baseada numa prática esportiva escolar no sentido de experienciar várias atividades que estimulassem os domínios sociais e afetivos, cognitivos e motores. Isso oportuniza o convívio social, o desenvolvimento de atividades em grupo e o respeito às diferenças e particularidades de cada um. Considerando alguns princípios e condutas pedagógicas, como o estímulo a gostar de esporte, cuja prática, na hora do jogo, deve ser lúdica e também um aprendizado, havendo respeito aos colegas, e o entendimento do prazer de jogar com e não contra.

A construção de um processo metodológico pode enfatizar o lúdico no processo ensino-aprendizagem, mas também deve haver comprometimento de um ensino sério que seja competente para ensinar as várias formas de jogar. A tal forma que aqueles que já sabem jogar o façam da melhor maneira e aqueles que apresentam limitações, dificuldades (habilidades motoras e cognitivas) no jogar sejam orientados e incentivados até conseguirem fazê-lo, no mínimo, num nível suficiente.

Conforme Oliveira (2005), o resgate da ludicidade é um dos elementos que se destacam como possibilidade de trabalho numa proposição de "reinvenção" do esporte. Um passo importante para o avanço do resgate do lúdico é romper na escola, com a tentativa de separação absoluta entre jogo e esporte, no sentido de brincar de esportes, para tornar lúdica a tensão do esporte, para transformar o compromisso com a vitória em compromisso com a alegria e o prazer para todos. Huizinga (2000) cita o jogo como significante, o qual há algo "em jogo" (p.5), que vai além das necessidades da vida e que atribui um sentido à ação. $\mathrm{O}$ mesmo autor argumenta que a existência do jogo não está ligada a uma concepção, e sim que o ser humano possui a capacidade de entender que o jogo possui uma realidade autônoma e inegável.

Com a intervenção dos bolsistas do PIBID na prática de atividades físicas, houve um grande crescimento na formação inicial e maior envolvimento dos alunos na escola, através de uma atuação efetiva na área de Educação Física. Esse crescimento na formação inicial deu-se também pelas dificuldades encontradas pelos acadêmicos, principalmente perante aos alunos. As maiores dificuldades encontradas no decorrer do trabalho, foram à resistência dos alunos em não querer praticar as atividades e sim somente jogar, além dos meninos se recusarem a jogar com as meninas. Outro fato marcante foi o domínio da turma pelos acadêmicos, pois como havia muitos alunos participando, havia momentos em que não obtinham silêncio e nem a atenção desses. A problemática é que alguns alunos não respeitavam o momento do professor explicar e interagir com a atividade, dificultando assim, a atenção da maioria da turma.

As dificuldades encontradas eram repassadas para todo o grupo de bolsistas, supervisor do programa e também para as professoras da escola para que, juntos pudesse buscar resoluções. Com essas atitudes, o acadêmico a cada aula exibia uma estratégia e, além disso, priorizava o diálogo com seus alunos para que houvesse a solução do problema.

Com relação atuação pedagógica, evidenciou-se uma troca de experiência 
muito positiva, tanto para os bolsistas, quanto para os professores das turmas envolvidas, por meio de encontros pedagógicos de estudos semanalmente, o que representou ótimos resultados para o crescimento e motivação da área de Educação Física na escola em questão.

As estratégias utilizadas para o ensino da iniciação esportiva para os alunos foi uma forma de auxiliar no ensino-aprendizagem dos conteúdos, como o esporte. O método de proporcionar atividades e/ou jogos que possuíam semelhanças com o esporte a ser desenvolvido, facilitou aos alunos a compreender melhor os movimentos e as regras estabelecidas. A prática da iniciação esportiva objetiva a interação dos estudantes com os esportes, a vivência participativa, a demonstração dos movimentos e apresentação aos poucos das técnicas e táticas.

\section{CONSIDERAÇÕES FINAIS}

O subprojeto "Cultura Esportiva da Escola" através do PIBID demonstrou-se essencial para a formação inicial dos acadêmicos e para a formação continuada dos professores envolvidos. Os grupos de estudos realizados a partir da prática docente no ambiente escolar foram fundamentais para que houvesse a troca de conhecimentos e experiências pelos graduandos, dessa maneira foi possível estimulá-los a evoluir cada vez mais em sua área profissional.

O desenvolvimento das aulas ocorreu de forma mais atrativa e diversificada para que todos os alunos, no contexto das diferenças, pudessem participar. No início houve resistência, mas no decorrer das atividades os alunos compreenderam o verdadeiro objetivo do que estava sendo proposto. Além disso, os acadêmicos possuíam o auxílio das professoras da escola em questão, dos seus colegas e também do professor supervisor para que houvesse uma melhor atuação.

A partir do envolvimento entre acadêmicos e alunos durante as atividades complementares foi estimulada e construída resultados positivos em relação aos domínios social-afetivo, cognitivo e motor dos alunos, sendo que estes são vistos como um ser em formação, e, professores, agentes mediadores neste processo.

Desse modo, nas atividades realizadas não houve a busca de alunos que melhor se destacaram nos jogos, e sim a inclusão daqueles que possuíam maiores dificuldades de realizar a prática. $\mathrm{O}$ intuito era de que a aula pudesse tornar realmente o momento em que todos tinham a igual oportunidade de conhecer, compreender e participar o conteúdo proposto na sua essência. Compreende-se então que, o planejamento das aulas deve ser um companheiro inseparável neste percurso de valorização do trabalho de professor, pois é por meio de um planejamento é que se expõem os objetivos, o qual se quer alcançar.

Por fim, é correto afirmar que o comprometimento com a profissão é essencial, conseguindo assim, provar a importância e contribuição para o desenvolvimento dos alunos, exercendo nas escolas um papel como o de outra disciplina. Os educadores têm grande parcela de responsabilidade na formação integral do aluno, ao orientar, estimular, corrigir e mostrar caminhos.

\section{REFERÊNCIAS}

BETTI, M.; ZULIANI, L. R.; Educação Física escolar: uma proposta de diretrizes 
pedagógicas. Revista Mackenzie de Educação Física e Esporte. São Paulo, V.1, N.1, p.73-82, 2002.

BRACHT, V. Educação Física no 1o. grau: Conhecimento e Especificidade. Rev. paul. Educ. Fís., São Paulo, supl.2, p.2328, 1996. Disponível em: http://citrus. uspnet.usp.br/eef/uploads/arquivo/ v10\%20supl $2 \% 20$ artigo4.pdf Acessado em 05 de abril de 2012.

COLETIVO DE AUTORES. Metodologia do Ensino de Educação Física. São Paulo; Cortez, 1992.

FENSTERSEIFER, P. E. A responsabilidade social da educação escolar (ou a "escola como instituição republicana"). In: MASS, A. K.; ALMEIDA, A. L.; ANDRADAE, E. (Orgs.). Linguagem, escrita e mundo. ljuí: Unijuí, 2006.

GONZÁlEZ, F. J. Projeto curricular e educação física: o esporte como conteúdo escolar. In: REZER, Ricardo (org.). O fenômeno esportivo: ensaios crítico-reflexivos. Chapecó: Argos, 2006. p. 69-109.

HUIZINGA, J. Homo Ludens. Cap. I: Natureza e Significado do Jogo como Fenômeno Cultural. Tradução: João Paulo Monteiro - Homo Ludens - vom Unprung der Kultur im Spiel. Editora Perspectiva S.A., 2000.

KUNZ, E.; Transformação didática pedagógica do esporte / Elenor Kunz. 7. Ed. Ijuí: Ed. Unijuí, 2006. - 160 p. (Coleção educação física).
LIÇÕES DO RIO GRANDE: Linguagens Códigos e Suas Tecnologias Arte e Educação Física - Caderno Do Professor - Ensino Fundamental e Ensino Médio. 2010

OLIVEIRA, A. A. B. Planejando a educação física escolar. In: VIEIRA, José Luiz Lopes. Educação física e esportes: estudos e proposições. Maringá, PR: Eduem, 2004. p.25-55.

OLIVEIRA, S. ASSIS de. Reinventando o esporte: possibilidades de prática pedagógica/ Sávio Assis de Oliveira. -2. Ed. - Campinas, SP: Autores Associados, chancela editorial CBCE, 2005. (Coleção educação física e esportes).

OLIVEIRA, V.; PAES, R. R. A pedagogia da iniciação esportiva: um estudo sobre o ensino dos jogos desportivos coletivos. Revista Digital Lecturas: Educación Física y Deportes Buenos Aires: ano 10, n. 71, abr. 2004.www.efdeportes.com/ efd71/jogos.htm

QUADROS, R. B; SAWITZKI, R. L. A cultura esportiva escolar: a ponte entre universidade e escola. EFDeportes.com, Revista Digital. Buenos Aires, Año 16, No 161, Octubre de 2011. http://www. efdeportes.com/

SAWITZKI, R. L. Regime de colaboração, projeto político pedagógico e desporto escolar. UNI revista - Vol. 1, $\mathrm{n}^{\circ} 2$, abril 2006. 
V. $26, \mathrm{n}^{\circ} 42$, junho/2014

PRACTICE OF SPORTS CULTURE IN PHYSICAL EDUCATION CLASSES

\begin{abstract}
This work aims to demonstrate the practice of sports initiation in Physical Education classes as complementary activities, emphasizing the development of students. The study was based on a report of an experience that was developed with the 6th year in a State School through the Subproject "Culture Sports School" Federal University of Santa Maria. The project has provided diversified classes for all students in the context of their differences, can participate in this way it is possible to encourage them in the fields motor, cognitive, affective and social. Despite the difficulties encountered during the teaching practice, there were positive results in ongoing activities.
\end{abstract}

Key-words: Schoolar Phycal Education; Professional Interview; Sports pedagogy.

Recebido em: abril/2013

Aprovado em: fevereiro/2014 